\title{
Anti-inflammatory properties of a dual PPARgamma/alpha agonist muraglitazar in in vitro and in vivo models
}

\author{
Erja-Leena Paukkeri ${ }^{1}$, Tiina Leppänen ${ }^{1}$, Mira Lindholm', Mun Fei Yam², Mohd Zaini Asmawi ${ }^{2}$, Anne Kolmonen², \\ Paula $\mathrm{H}$ Aulaskari ${ }^{3}$ and Eeva Moilanen ${ }^{1 *}$
}

\begin{abstract}
Introduction: Peroxisome proliferator-activated receptor (PPAR) agonists are widely used drugs in the treatment of diabetes and dyslipidemia. In addition to their metabolic effects, PPAR isoforms PPAR $\alpha$ and PPAR $\gamma$ are also involved in the regulation of immune responses and inflammation. In the present study, we investigated the effects of a dual PPAR $\gamma / \alpha$ agonist muraglitazar on inflammatory gene expression in activated macrophages and on carrageenan-induced inflammation in the mouse.

Methods: $J 774$ murine macrophages were activated by lipopolysaccharide (LPS) and treated with dual PPAR $/ \alpha$ agonist muraglitazar, PPAR $\gamma$ agonist GW1929 or PPAR $\alpha$ agonist fenofibrate. The effects of PPAR agonists on cytokine production and the activation of inducible nitric oxide synthase (iNOS) pathway were investigated by ELISA, Griess method, Western blotting and quantitative RT-PCR. Nuclear translocation, DNA-binding activity and reporter gene assays were used to assess the activity of nuclear factor kappa B (NF-kB) transcription factor. Carrageenan-induced paw oedema was used as an in vivo model of acute inflammation.
\end{abstract}

Results: Muraglitazar as well as PPAR $\gamma$ agonist GW1929 and PPAR $\alpha$ agonist fenofibrate inhibited LPS-induced iNOS expression and NO production in activated macrophages in a dose-dependent manner. Inhibition of iNOS expression by muraglitazar included both transcriptional and post-transcriptional components; the former being shared by GW1929 and the latter by fenofibrate. All tested PPAR agonists also inhibited IL-6 production, while TNF $\alpha$ production was reduced by muraglitazar and GW1929, but not by fenofibrate. Interestingly, the antiinflammatory properties of muraglitazar were also translated in vivo. This was evidenced by the finding that muraglitazar inhibited carrageenan-induced paw inflammation in a dose-dependent manner in mice as did iNOS inhibitor L-NIL and anti-inflammatory steroid dexamethasone.

Conclusions: These results show that muraglitazar has anti-inflammatory properties both in vitro and in vivo and these effects reflect the agonistic action through both PPAR $\alpha$ and PPAR $\gamma$.

\section{Introduction}

It has long been known that macrophages are pivotal cells in the pathogenesis of autoimmune diseases, including rheumatoid arthritis [1,2]. During the last decades macrophages have also been found to affect metabolism in various tissues and today it is widely agreed that macrophages are also associated with the pathophysiology of

\footnotetext{
* Correspondence: eeva.moilanen@uta.fi

'The Immunopharmacology Research Group, University of Tampere School of Medicine and Tampere University Hospital, Medisiinarinkatu 3, Tampere, Fl-33014, Finland

Full list of author information is available at the end of the article
}

many obesity-linked diseases [3-5]. The mechanisms connecting macrophage activation and metabolism are not fully known but some hypotheses have been proposed. Macrophages are present in adipose tissue and when aberrantly activated in relation to obesity they produce inflammatory factors by themselves and also activate surrounding adipocytes to release signalling proteins called adipokines. Adipokines are known to regulate energy metabolism and appetite but also inflammatory responses, arthritis and catabolic processes in articular cartilage [6]. It is also obvious that obesity-related changes in energy

\section{Biomed Central}


metabolism directly regulate macrophage responses [7]. From the pharmacological point of view, an interesting question exists of if or how the macrophage phenotype and secretory profile differ between chronic inflammation typical, for example, in rheumatoid arthritis and obesityrelated systemic inflammation, and if the same known and future anti-inflammatory compounds would have therapeutic value in only one or both of those inflammatory conditions.

Peroxisome proliferator-activated receptors (PPARs) are members of the nuclear receptor superfamily and they are strongly linked to the regulation of energy homeostasis in cells. PPARs are expressed in three isoforms: PPAR $\alpha, \operatorname{PPAR} \gamma$ and PPAR $\beta / \delta$. PPAR $\gamma$ agonists thiazolidinediones (TZDs) and PPAR $\alpha$ agonist fibrates are widely used as pharmacological agents in the treatment of diabetes and dyslipidemia, respectively. Although the main interest in PPAR-related studies has been focused on the role of PPARs in energy homeostasis, PPARs, especially PPAR $\alpha$ and PPAR $\gamma$, are also shown to be involved in the regulation of the immune and inflammatory responses in obesity-linked diseases [8-10]. During the last few years some reports have been published showing that PPAR $\gamma$ agonists reduce inflammatory responses in animal models of rheumatoid arthritis [11]. Nevertheless, we found only a single study suggesting that also a PPAR $\alpha$ agonist fenofibrate would have antiinflammatory effects in experimentally induced arthritis [12].

Muraglitazar is a dual PPAR $\gamma / \alpha$-agonist that has strong PPAR $\gamma$ and moderate PPAR $\alpha$ effects [13]. Originally, it was developed for the treatment of type II diabetes with a view to combining both insulin sensitizing and antihyperlipidemic effects of the PPAR agonists. Muraglitazar has been shown to decrease the levels of $\mathrm{HbA}_{1 \mathrm{c}}$, FFA and triglycerides and to increase the levels of HDL in humans when compared to placebo, and it appeared to be more potent than pioglitazone $[14,15]$. However, despite the fact that there are several reports on the antidiabetic effects of muraglitazar, there are no previous studies on the effects of muraglitazar in inflammatory processes.

In the present study, we aimed to investigate the antiinflammatory effects of muraglitazar. Since the immunoregulatory effects of PPAR $\alpha$ and PPAR $\gamma$ are somewhat different, we wanted to study whether muraglitazar has more potent anti-inflammatory effects than PPAR $\gamma$ or PPAR $\alpha$ agonists alone. To examine this we investigated the effects of muraglitazar on the activation of the inducible nitric oxide synthase (iNOS) pathway and on the production of inflammatory cytokines in activated macrophages. We extended our study by testing the effect of muraglitazar on carrageenan-induced paw inflammation in the mouse.

\section{Materials and methods Materials}

Reagents were obtained as follows: GW1929 and MG132 from Tocris Bioscience (Bristol, UK), $\mathrm{N}^{6}$-(1-iminoethyl)-L-lysine (L-NIL) from Enzo Life Sciences Ltd. (Exeter, UK), rabbit polyclonal $\beta$-actin, lamin $\mathrm{A} / \mathrm{C}$ and iNOS antibodies and goat HRP-conjugated anti-rabbit polyclonal antibody from Santa Cruz Biotechnology Inc. (Santa Cruz, CA, USA). Nuclear factor kappa B (NF- $\kappa$ B) subunit p65 antibody was from Cell Signaling Technology Inc. (Danvers, MA, USA). Muraglitazar was synthesised in the laboratory of Dr. Paula H. Aulaskari (University of Eastern Finland, Joensuu Campus, Joensuu, Finland), see below. Other reagents were from Sigma-Aldrich Co. (St. Louis, MO, USA).

Muraglitazar was synthesised by a five-step procedure according to Devasthale et al. [13]. The structure and purity of intermediates and the final product muraglitazar were confirmed by melting point analysis (Gallenkamp melting point apparatus MFB-595, Gallenkamp, Loughborough, UK), ${ }^{1} \mathrm{H},{ }^{13} \mathrm{C}$ NMR spectroscopy (Bruker Avance $250 \mathrm{MHz}$ and $400 \mathrm{MHz}$ spectrometer, Bruker BioSpin AG, Fällanden, Switzerland) using deuteriumchloroform as a solvent and tetramethylsilane as a reference, and by IR spectroscopy (Nicolet Avatar 320 FT-IR spectrometer, Thermo Electron Scientific Instruments, LLC, Madison, WI, USA) using dry potassium bromide as a salt component of solid mixture. The molecular structure and the purity of muraglitazar were also confirmed by mass spectrometer and elemental analysis. The mass spectrometer measurements were performed on Bruker BioAPEX II 47e Fourier transform ion cyclotron resonance (FTICR) mass spectrometer (Bruker Daltonics, Billerica, MA, USA) equipped with an InfinityTM cell, 4.7 Tesla 160-mm-bore superconducting magnet (Magnex Scientific Ltd., Abingdon, UK), and an external electron ionization (EI) or electrospray ion source (ESI) (Analytica of Branford Inc., Branford, CT, USA). Elemental analysis was performed on CE Instruments EA 1110 elemental analyser (CE Instruments Ltd., Rodano, MI, Italy). The results of elemental analysis were within $\pm 0.2 \%$ of the theoretical values.

\section{Cell culture}

Murine J774 macrophages (American Type Culture Collection, Manassas, VA, USA) were cultured at $37^{\circ} \mathrm{C}$ in $5 \% \mathrm{CO}_{2}$ atmosphere in Dulbecco's modified Eagle's medium with Ultraglutamine 1 (Lonza Group Ltd., Basel, Switzerland) supplemented with 10\% heat-inactivated foetal bovine serum (Lonza Group Ltd), $100 \mathrm{U} / \mathrm{ml}$ penicillin, $100 \mu \mathrm{g} / \mathrm{ml}$ streptomycin and $250 \mathrm{ng} / \mathrm{ml}$ amphotericin B (Invitrogen Co., Carlsbad, CA, USA) and harvested with trypsin-EDTA (Invitrogen Co.). Cells were seeded on 24-well plates for RNA extraction and 
nitrite and ELISA measurements, on 24-well plates or 6well plates for preparation of cell lysates for Western blotting, on $10 \mathrm{~cm}$ dishes for preparation of nuclear extracts for Western blotting and NF- $\kappa$ B p 65 DNA binding assay and on 96-well plates for an XTT test. Confluent cultures were exposed to fresh culture medium containing the compounds of interest.

Human HEK293 cells (American Type Culture Collection) were cultured at $37^{\circ} \mathrm{C}$ in $5 \% \mathrm{CO}_{2}$ atmosphere in Eagle's minimal essential medium (Lonza Group Ltd.) supplemented with $0.15 \%$ sodium bicarbonate, $100 \mu \mathrm{M}$ non-essential aminoacids, $1 \mathrm{mM}$ sodium pyruvate, $10 \%$ heat-inactivated foetal bovine serum (Lonza Group Ltd), $100 \mathrm{U} / \mathrm{ml}$ penicillin, $100 \mu \mathrm{g} / \mathrm{ml}$ streptomycin and $250 \mathrm{ng} / \mathrm{ml}$ amphotericin B (Invitrogen Co.) and harvested with trypsinEDTA (Invitrogen Co.). Cells were seeded on 24-well plates for RNA extraction. Confluent cultures were exposed to fresh culture medium containing the compounds of interest.

Cell viability after treatment with combinations of LPS or cytokine mixture and the tested compounds was assessed by modified XTT test (Cell Proliferation Kit II, Roche Diagnostics, Mannheim, Germany) according to the manufacturer's instructions.

\section{Preparation of stable J774-pGL4(miNOS-prom)neo and HEK293-pNF- $\kappa$ B(luc)neo reporter cell lines}

The pGL-MNOS II-5'-Luc plasmid [16] containing 5'flanking sequence $(1,171 \mathrm{bp}$, positions $-1,570$ to +141 ; promoter and a part of exon 1) of the murine iNOS gene was provided by Professor Harmut Kleinert (Johannes Gutenberg University, Mainz, Germany). This plasmid was digested with KpnI and HindIII, and the restriction fragment, containing murine iNOS promoter and part of exon 1, was then cloned into the KpnI/HindIII site of firefly luciferase reporter plasmid pGL4.17(luc2/neo) (Promega, Madison, WI, USA) generating pGL4(miNOSprom)neo, in which the luciferase gene is driven by murine iNOS promoter. The plasmid was sequenced to confirm the appropriate size, position and orientation of the insert in the plasmid. To create a stable transfection with murine iNOS promoter reporter plasmid, J774 cells were transfected with pGL4(miNOS-prom)neo using Lipofectamine 2000 (Invitrogen Co.) according to the manufacturer's instructions. Transfected cells were selected with G418 disulfate salt (Sigma-Aldrich Co.) treatment $(800 \mu \mathrm{g} / \mathrm{ml})$. After the selection, the survived clones were pooled to give rise to J774-pGL4(miNOSprom)neo cell line and further cultured in the presence of $400 \mu \mathrm{g} / \mathrm{ml}$ of G418.

To create a stable transfection with NF- $\kappa \mathrm{B}$ reporter plasmid, HEK293 cells were transfected with pGL4.32 [luc2P/NF- $\kappa$ B-RE/Hygro] (Promega) using Lipofectamine 2000 (Invitrogen Co.) according to the manufacturer's instructions. Transfected cells were selected with hygromycin B (EMD Biosciences Inc., La Jolla, CA, USA) treatment $(200 \mu \mathrm{g} / \mathrm{ml})$. After the selection, the survived clones were pooled to give rise to HEK293- pGL4.32[luc2P/NF$\kappa \mathrm{B}-\mathrm{RE} / \mathrm{Hygro}]$ cell line and further cultured in the presence of $100 \mu \mathrm{g} / \mathrm{ml}$ of hygromycin B.

\section{Nitrite determination}

Nitrous oxide (NO) production was determined by measuring the accumulation of nitrite, a stable metabolite of $\mathrm{NO}$ in aqueous condition, into the culture medium. The culture medium was collected at indicated time points and nitrite was measured by the Griess reaction [17].

\section{Preparation of cell lysates for Western blotting}

At indicated time points, the cells were rapidly washed with ice-cold phosphate-buffered saline and solubilized in cold lysis buffer containing $10 \mathrm{mM}$ Tris-base, $\mathrm{pH}$ 7.4, 5 mM EDTA, $50 \mathrm{mM} \mathrm{NaCl}, 1 \%$ Triton X-100, $0.5 \mathrm{mM}$ phenylmethylsulphonyl fluoride, $1 \mathrm{mM}$ sodium orthovanadate, $20 \mu \mathrm{g} / \mathrm{ml}$ leupeptin, $50 \mu \mathrm{g} / \mathrm{ml}$ aprotinin, $5 \mathrm{mM}$ $\mathrm{NaF}, 2 \mathrm{mM}$ sodium pyrophosphate and $10 \mu \mathrm{M}$ n-octyl- $\beta$ $\mathrm{D}$-glucopyranoside. After incubation on ice for $15 \mathrm{~min}$ utes, lysates were centrifuged $\left(13,400 \mathrm{~g}, 4^{\circ} \mathrm{C}, 10\right.$ minutes), supernatants were collected and mixed 3:1 with SDS sample buffer $(62.5 \mathrm{mM}$ Tris- $\mathrm{HCl}, \mathrm{pH} 6.8,10 \%$ glycerol, $2 \%$ SDS, $0.025 \%$ bromophenol blue and $5 \% \beta$-mercaptoethanol). The samples were stored at $-20^{\circ} \mathrm{C}$ until analysed. An aliquot of the supernatant was used to determine protein concentration by the Coomassie blue method [18].

\section{Preparation of nuclear extracts for Western blotting}

At indicated time points, the cells were rapidly washed with ice-cold phosphate-buffered saline and solubilized in hypotonic buffer A (10 mM HEPES-KOH, pH 7.9, 1.5 mM $\mathrm{MgCl}_{2}, 10 \mathrm{mM} \mathrm{KCl}, 0.5 \mathrm{mM}$ dithiothreitol, $0.2 \mathrm{mM}$ phenylmethylsulphonyl fluoride, $1 \mathrm{mM}$ sodium orthovanadate, $10 \mu \mathrm{g} / \mathrm{ml}$ leupeptin, $25 \mu \mathrm{g} / \mathrm{ml}$ aprotinin, $1 \mathrm{mM} \mathrm{NaF}$ and $0.1 \mathrm{mM}$ EGTA). After incubation on ice for 10 minutes, the cells were vortexed for 30 seconds and the nuclei were separated by centrifugation at $4^{\circ} \mathrm{C}, 21,000 \mathrm{~g}$ for 10 seconds. Nuclei were resuspended in buffer C (20 mM HEPES$\mathrm{KOH}, \mathrm{pH} 7.9,25 \%$ glycerol, $420 \mathrm{mM} \mathrm{NaCl}, 1.5 \mathrm{mM}$ $\mathrm{MgCl}_{2}, 0.5 \mathrm{mM}$ dithiothreitol, $0.2 \mathrm{mM}$ phenylmethylsulphonyl fluoride, $1 \mathrm{mM}$ sodium orthovanadate, $10 \mu \mathrm{g} / \mathrm{ml}$ leupeptin, $25 \mu \mathrm{g} / \mathrm{ml}$ aprotinin, $1 \mathrm{mM} \mathrm{NaF}$ and $0.1 \mathrm{mM}$ EGTA) and incubated on ice for 20 minutes. Nuclei were vortexed for 30 seconds and nuclear extracts were obtained by centrifugation at $4^{\circ} \mathrm{C}, 21,000 \mathrm{~g}$ for 2 minutes. Supernatants were collected and mixed 3:1 with SDS sample buffer. The samples were stored at $-70^{\circ} \mathrm{C}$ until analysed. Coomassie blue method was used to measure the protein content of the samples [18]. 


\section{Western blotting}

Prior to Western blotting, samples were boiled for 10 minutes and $20 \mu \mathrm{g}$ of protein was loaded per lane on $10 \%$ or $12 \%$ SDS-polyacrylamide gels and separated by electrophoresis. Proteins were transferred to Hybond enhanced chemiluminescence nitrocellulose membrane (GE Healthcare, Little Chalfont, Buckinghamshire, UK). After the transfer, the membrane was blocked in TBS/T (20 mM Tris-base pH 7.6, $150 \mathrm{mM} \mathrm{NaCl}, 0.1 \%$ Tween20) containing $5 \%$ of non-fat dry milk or $5 \%$ bovine serum albumin at room temperature for one hour and incubated with primary antibody in the blocking solution at $4^{\circ} \mathrm{C}$ overnight. The membrane was washed with TBS/T, incubated with secondary antibody in the blocking solution at room temperature for one hour and washed. Bound antibody was detected using SuperSignal West Pico or Dura chemiluminescent substrate (Pierce, Rockford, IL, USA) and ImageQuant LAS 4000 mini imaging system (GE Healthcare). The chemiluminescent signal was quantified with ImageQuant TL 7.0 image analysis software.

\section{RNA extraction and quantitative real-time PCR}

At the indicated time points, culture medium was removed and total RNA of the cultured cells was extracted using GenElute ${ }^{\mathrm{TM}}$ Mammalian Total RNA Miniprep kit (Sigma-Aldrich Co.). For luciferase mRNA experiments, total RNA was treated with DNase I (Fermentas UAB, Vilnius, Lithuania). Total RNA (100 ng) was reversetranscribed to cDNA using TaqMan Reverse Transcription reagents and random hexamers (Applied Biosystems, Foster City, CA, USA). cDNA obtained from the reverse transcription reaction was diluted 1:20 with RNase-free water and was subjected to quantitative PCR using TaqMan Universal PCR Master Mix and ABI Prism 7000 sequence detection system (Applied Biosystems).

Total RNA of the tissue samples was extracted by GenElute $^{\mathrm{TM}}$ Mammalian Total RNA Miniprep kit with proteinase $\mathrm{K}$ digestion (Sigma-Aldrich Co.). Total RNA (500 ng) was reverse-transcribed to cDNA using Maxima First Strand cDNA Synthesis Kit (Fermentas UAB). cDNA obtained from the reverse transcription reaction was diluted 1:20 with RNase-free water and was subjected to quantitative PCR using TaqMan Universal PCR Master Mix and ABI Prism 7000 sequence detection system (Applied Biosystems).

Primers and probes for luciferase, IL-6, iNOS and glyceraldehyde-3-phosphate dehydrogenase (GAPDH) (Table 1) were optimized according to the manufacturer's instructions in TaqMan Universal PCR Master Mix Protocol part number 4304449 revision $C$. The expression of mouse TNF $\alpha$ mRNA was measured by using TaqMan ${ }^{\circledR}$ Gene Expression Assay (Mm00443260_g1, Applied Biosystems, Foster City, CA, USA).
Table 1 Primer and probe sequences.

\begin{tabular}{|c|c|c|}
\hline Gene & Oligonucleotide & Sequence $5^{\prime} \rightarrow 3^{\prime}$ \\
\hline \multirow{3}{*}{$\begin{array}{l}\text { Human } \\
\text { GAPDH }\end{array}$} & Forward primer & TCCTACCACCAGCAACCCTGCCA \\
\hline & Reverse primer & GCAACAATATCCACTTTACCAGAGTTAA \\
\hline & Probe & CGCCTGGTCACCAGGGCTGC \\
\hline \multirow[t]{3}{*}{ Luciferase } & Forward primer & ACGGCTTCGGCATGTTCA \\
\hline & Reverse primer & CTCCTCCTCGAAGCGGTACA \\
\hline & Probe & TTGATCTGCGGCTITCGGGTCGT \\
\hline \multirow{2}{*}{$\begin{array}{l}\text { Mouse } \\
\text { GAPDH }\end{array}$} & Forward primer & GCATGGCCTTCCGTGTTC \\
\hline & Reverse primer & GATGTCATCATACTTGGCAGGTIT \\
\hline \multirow[t]{4}{*}{ Mouse IL-6 } & Probe & TCGTGGATCTGACGTGCCGCC \\
\hline & Forward primer & TCGGAGGCTTAATTACACATGTTC \\
\hline & Reverse primer & CAAGTGCATCATCGTTGTTCATAC \\
\hline & Probe & CAGAATTGCCATTGCACAACTCTITTCTCA \\
\hline \multirow{3}{*}{$\begin{array}{l}\text { Mouse } \\
\text { iNOS }\end{array}$} & Forward primer & CCTGGTACGGGCATTGCT \\
\hline & Reverse primer & GCTCATGCGGCCTCCTT \\
\hline & Probe & CAGCAGCGGCTCCATGACTCCC \\
\hline
\end{tabular}

PCR reaction parameters were as follows: incubation at $50^{\circ} \mathrm{C}$ for 2 minutes, incubation at $95^{\circ} \mathrm{C}$ for $10 \mathrm{~min}$ utes, and thereafter 40 cycles of denaturation at $95^{\circ} \mathrm{C}$ for $15 \mathrm{~s}$ and annealing and extension at $60^{\circ} \mathrm{C}$ for $1 \mathrm{~min}$ ute. Each sample was determined in duplicate.

The relative mRNA levels were quantified and compared using the relative standard curve method as described in Applied Biosystems User Bulletin number 2.

\section{NF- $\kappa$ B p65 DNA binding assay}

DNA binding activity of NF- $\kappa$ B p 65 was evaluated using NF- $\kappa$ B (p65) Transcription Factor Assay Kit (Cayman Chemical Company, Ann Arbor, MI, USA). The nuclear extracts for the assay were prepared according to the manufacturer's instructions and $10 \mu \mathrm{g}$ of nuclear protein per well was used for the experiment. The samples were incubated at $+4^{\circ} \mathrm{C}$ overnight with the dsDNA templates carrying NF- $\kappa \mathrm{B}$ response element. After primary (anti-NF- $\kappa \mathrm{B}$ p65) and secondary (goat anti-rabbit HRP) antibody treatments, developing reagents were added and absorbance was read at $450 \mathrm{~nm}$.

\section{Enzyme-Linked Immunosorbent Assay (ELISA)}

Culture medium samples were kept at $-20^{\circ} \mathrm{C}$ until assayed. The concentrations of IL- 6 and TNF $\alpha$ in culture medium were determined by ELISA according to the manufacturer's instructions (R\&D Systems Europe, Abingdon, UK).

\section{Carrageenan-induced paw oedema in the mouse}

Prior to the experiment investigating the time dependent formation of carrageenan-induced paw oedema, 36 male Charles River mice (weighing 25.0 to $30.0 \mathrm{~g}$ ) were housed 
and cared for under the guidelines of the institutional animal care and use committee with food and water provided ad libitum. The study was approved by the Animal Ethic Committee, Universiti Sains Malaysia.

The animals were randomly divided into six groups (six mice per group) and each group was treated orally with the test compound suspended in $2.0 \%(\mathrm{w} / \mathrm{v})$ carboxymethyl cellulose (CMC) in distilled water. The test groups were as follows: control (treated with $2.0 \% \mathrm{CMC}$ only), muraglitazar $12.5 \mathrm{mg} / \mathrm{kg}$, muraglitazar $25 \mathrm{mg} / \mathrm{kg}$, muraglitazar $50 \mathrm{mg} / \mathrm{kg}$, L-NIL $50 \mathrm{mg} / \mathrm{kg}$ and dexamethasone $2 \mathrm{mg} / \mathrm{kg}$. An hour after the treatment, $40 \mu \mathrm{l}$ of carrageenan ( $1 \%$ suspension in normal saline) was injected subcutaneously into the left hind paws of the animals. Thicknesses of the paws were measured by micrometer one hour before and one hour, four hours and six hours after the carrageenan injection. The results are expressed as percentages of swelling calculated as follows:

Difference $=($ thickness of the hind paw at indicated time point - thickness of the hind paw before carrageenan)/thickness of the hind paw before carrageenan.

The carrageenan-induced gene expression was investigated in C57BL/6 mice. The study was approved by the Animal Care and Use Committee of the University of Tampere and the respective provincial committee for animal experiments. Animals were housed under standard conditions of light, temperature and humidity (12:12 h light-dark cycle, $22 \pm 1^{\circ} \mathrm{C}, 50$ to $\left.60 \%\right)$ with food and water provided ad libitum.

Mice were randomly divided into two study groups with five and seven mice in the groups and muraglitazar $50 \mathrm{mg} /$ $\mathrm{kg}$ was injected intraperitoneally into the group of five mice. Two hours after the treatment, the mice were anesthetized with an intraperitoneal injection of $0.5 \mathrm{mg} / \mathrm{kg}$ of medetomidine (Orion Oyj, Espoo, Finland) and $75 \mathrm{mg} /$ $\mathrm{kg}$ of ketamine (Pfizer Oy Animal Health, Helsinki, Finland), and $30 \mu \mathrm{l}$ of $\lambda$-carrageenan (1.5\% suspension in normal saline) was injected subcutaneously into a hind paw of the animals. As a control, $30 \mu \mathrm{l}$ of saline was injected into the contralateral paws. The paw volumes were measured before and six hours after carrageenan injection by plethysmometer (Ugo Basile Srl, Comerio, Italy). Oedema is expressed as the difference between the change in carrageenan-treated paw volume and the control paw volume in $\mu \mathrm{l}$. After six hours of carrageenan injection, the mice were sacrificed by cervical dislocation. Carrageenan-treated and control paws were skinned and the soft tissues of the paws were collected and RNA was extracted as described above.

\section{Statistics}

Results are expressed as mean + standard error of mean (SEM). When indicated, statistical significance was calculated by analysis of variance followed by Dunnett's multiple comparisons test or Mann-Whitney test. Differences were considered significant at $P<0.05$.

\section{Results \\ Muraglitazar and PPAR $\alpha$ and PPAR $\gamma$ agonists decreased NO production and iNOS expression}

Resting J774 macrophages did not produce detectable amounts of NO, but when the cells were activated through TLR4 pathway by bacterial endotoxin LPS, NO production and iNOS expression were increased. Muraglitazar, PPAR $\alpha$ agonist fenofibrate and PPAR $\gamma$ agonist GW1929 decreased LPS-induced iNOS expression (Figure 1) and NO production (Figure 2) in a dosedependent manner. Muraglitazar, fenofibrate or GW1929 did not affect cell viability at the concentration used as determined by XTT test.

\section{Muraglitazar and a PPAR $\gamma$ agonist, but not a PPAR $\alpha$ agonist, reduced iNOS mRNA expression}

Since all three PPAR agonists decreased iNOS expression and NO production, we went further and determined the effects of PPAR agonists on iNOS mRNA expression. Muraglitazar and GW1929 reduced the levels of iNOS mRNA when determined six hours after the addition of LPS. However, fenofibrate had no effect on iNOS mRNA levels as compared to the cells treated with LPS only. NF- $\kappa$ B inhibitor MG132 was used as a control compound and it reduced LPS-induced iNOS mRNA levels as expected (Figure 3a).

Since the reduction of iNOS mRNA levels may be a sign of either transcriptional inhibition or increase in iNOS mRNA degradation, we studied the effect of PPAR agonists on the half-life of iNOS mRNA. After six-hour incubation with LPS alone or together with PPAR agonists, actinomycin D was added to the cells to stop mRNA synthesis. Incubations were terminated at different time points after the addition of actinomycin D. None of the PPAR agonists did affect the stability of iNOS mRNA when compared to the cells treated with LPS only (Figure $3 \mathrm{~b}$ ). These results suggest that the suppressive effect of muraglitazar and GW1929 on LPSinduced iNOS mRNA levels is mediated at the level of iNOS transcription.

We further investigated the effect of muraglitazar on the activity of iNOS promoter in J774 macrophages stably transfected to express luciferase reporter gene under the control of full length murine iNOS promoter. Similar to the effects on iNOS mRNA levels in wild-type J774 cells, muraglitazar and GW1929, but not fenofibrate, reduced LPS-induced iNOS promoter activity (Figure 3c).

The different effects of fenofibrate and GW1929 on iNOS mRNA expression may be explained by our previous findings that $\mathrm{PPAR} \alpha$ agonists regulate iNOS expression at the post-transcriptional level [19]. To 


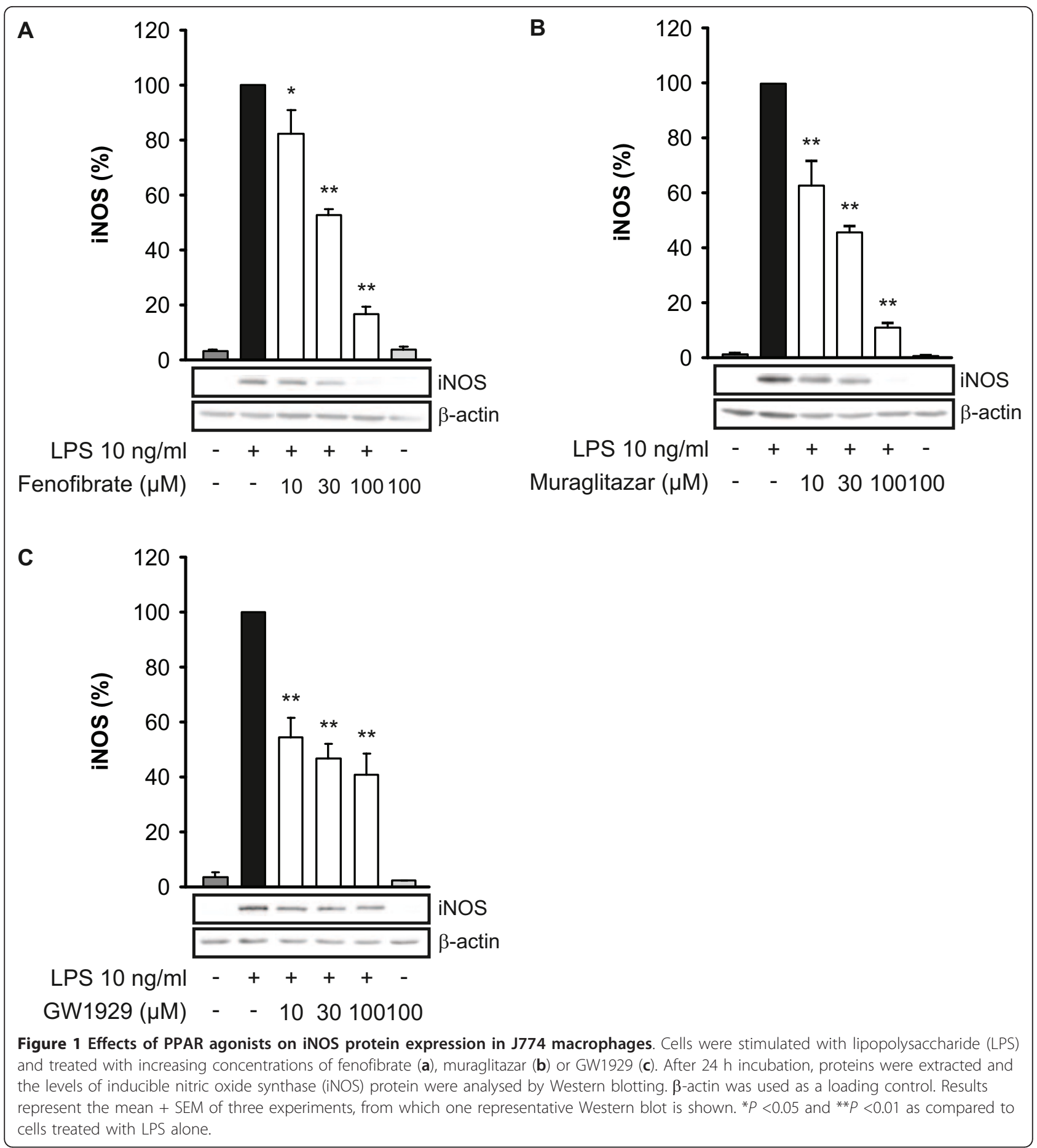

study the post-transcriptional effects of muraglitazar and the other two PPAR agonists on iNOS protein levels, we first stimulated J774 macrophages with LPS for 10 hours, and PPAR agonists were added thereafter for 14 hours. Muraglitazar and fenofibrate, but not GW1929, were able to reduce iNOS protein levels in these posttranscriptional time points (Figure 3d).
Effects of muraglitazar and PPAR $\alpha$ and PPAR $\gamma$ agonists on TNF $\alpha$ and IL- 6 production

In order to investigate if PPAR agonists regulate the expression of other genes related to innate immunity, we measured their effects on IL- 6 and TNF $\alpha$ production. LPS induced TNF $\alpha$ and IL-6 production in J774 cells when measured with ELISA in the culture medium 
A

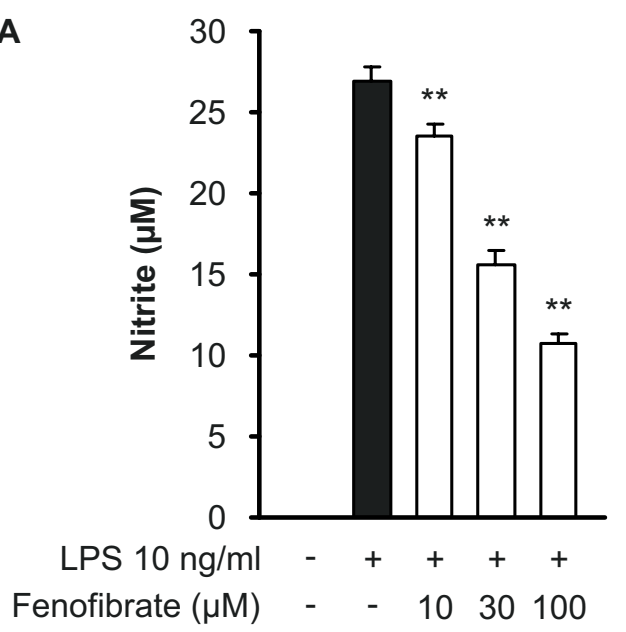

B

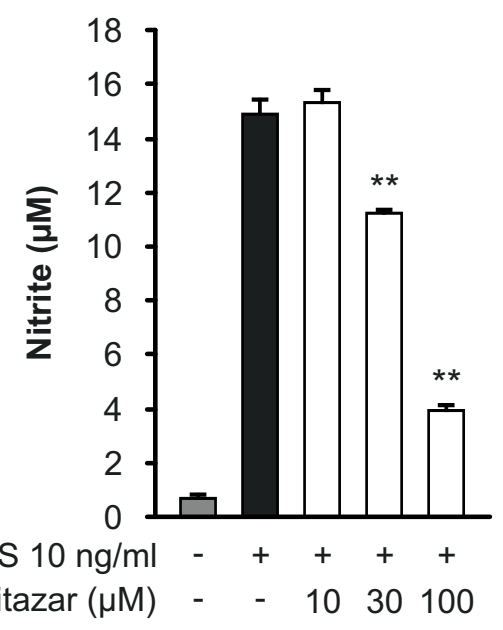

C

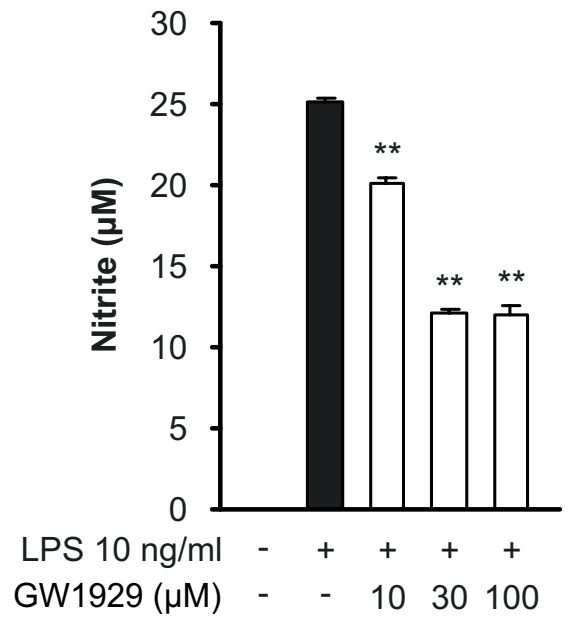

Figure 2 Effects of PPAR agonists on NO production in $\mathbf{J 7 7 4}$ macrophages. Cells were stimulated with lipopolysaccharide (LPS) and treated with increasing concentrations of fenofibrate (a), muraglitazar (b) or GW1929 (c). After 24 h incubation, nitrite accumulated into the culture medium was measured by Griess reaction as a marker of nitric oxide $(\mathrm{NO})$ production. Results represent the mean $+\operatorname{SEM}(n=6) .{ }^{*} P<0.01$ as compared to cells treated with LPS alone. after 24 hours incubation. All the agonists reduced IL-6 production in a dose-dependent manner (Figure 4). However, LPS-induced TNF $\alpha$ production was reduced only by GW1929 and muraglitazar at the highest concentration used (Figure 5c, b). Fenofibrate, on the other hand, tended to increase TNF $\alpha$ production at higher concentrations (Figure 5a).

\section{Muraglitazar or PPAR $\alpha$ or PPAR $\gamma$ agonists had no effect on NF- $\kappa$ B activation}

As we have reported in this paper, muraglitazar reduces the synthesis of iNOS, IL- 6 and TNFa. The syntheses of all these inflammatory markers are regulated by transcription factor NF- $\kappa \mathrm{B}[20,21]$. Therefore, we hypothesized that muraglitazar might affect the activity of NF$\kappa \mathrm{B}$.

To test this, we first investigated the effect of muraglitazar on the nuclear translocation of NF- $\kappa \mathrm{B}$. LPS enhanced the nuclear translocation of NF- $\kappa \mathrm{B}$ peaking at 30 minutes of stimulation. Muraglitazar, fenofibrate or GW1929 did not affect the nuclear levels of NF- $\kappa$ B p65 when compared to cells treated with LPS only (Figure 6a).

We continued by studying whether PPAR agonists affect the DNA binding activity of NF- $\kappa$ B. As illustrated in Figure 6b, muraglitazar, fenofibrate or GW1929 did not reduce the ability of NF- $\kappa \mathrm{B}$ to bind to dsDNA fragments containing NF- $\kappa$ B response element. NF- $\kappa$ B inhibitor pyrrolidine dithiocarbamate (PDTC) was used as a positive control compound and it reduced LPS-induced $\mathrm{NF}-\kappa \mathrm{B}$ binding as expected.

Further, we evaluated the effect of PPAR agonists on NF- $\kappa \mathrm{B}$-mediated transcription using HEK293 cells stably transfected with a luciferase reporter gene under the control of NF- $\kappa \mathrm{B}$-responsive promoter. PPAR agonists did not modulate NF- $\kappa \mathrm{B}$-mediated transcription while NF- $\kappa \mathrm{B}$ inhibitor PDTC had an effect as expected (Figure $6 c)$.

\section{Muraglitazar reduced carrageenan-induced inflammatory responses in the mouse}

To determine if the anti-inflammatory properties of muraglitazar are also translated to in vivo situations, we examined the effect of muraglitazar on carrageenaninduced inflammatory paw oedema in mice. Muraglitazar prevented the development of oedema in a dosedependent manner (Figure 7). With the highest dose of muraglitazar $(50 \mathrm{mg} / \mathrm{kg}$ ) used, carrageenan-induced oedema was reduced by $54 \%$ at the six-hour time point. Dexamethasone $2 \mathrm{mg} / \mathrm{kg}$ and iNOS inhibitor L-NIL 50 $\mathrm{mg} / \mathrm{kg}$ were used as control compounds and they reduced the oedema by $69 \%$ and $48 \%$, respectively.

In the following series of experiments, we analysed the effect of muraglitazar on inflammatory gene expression 


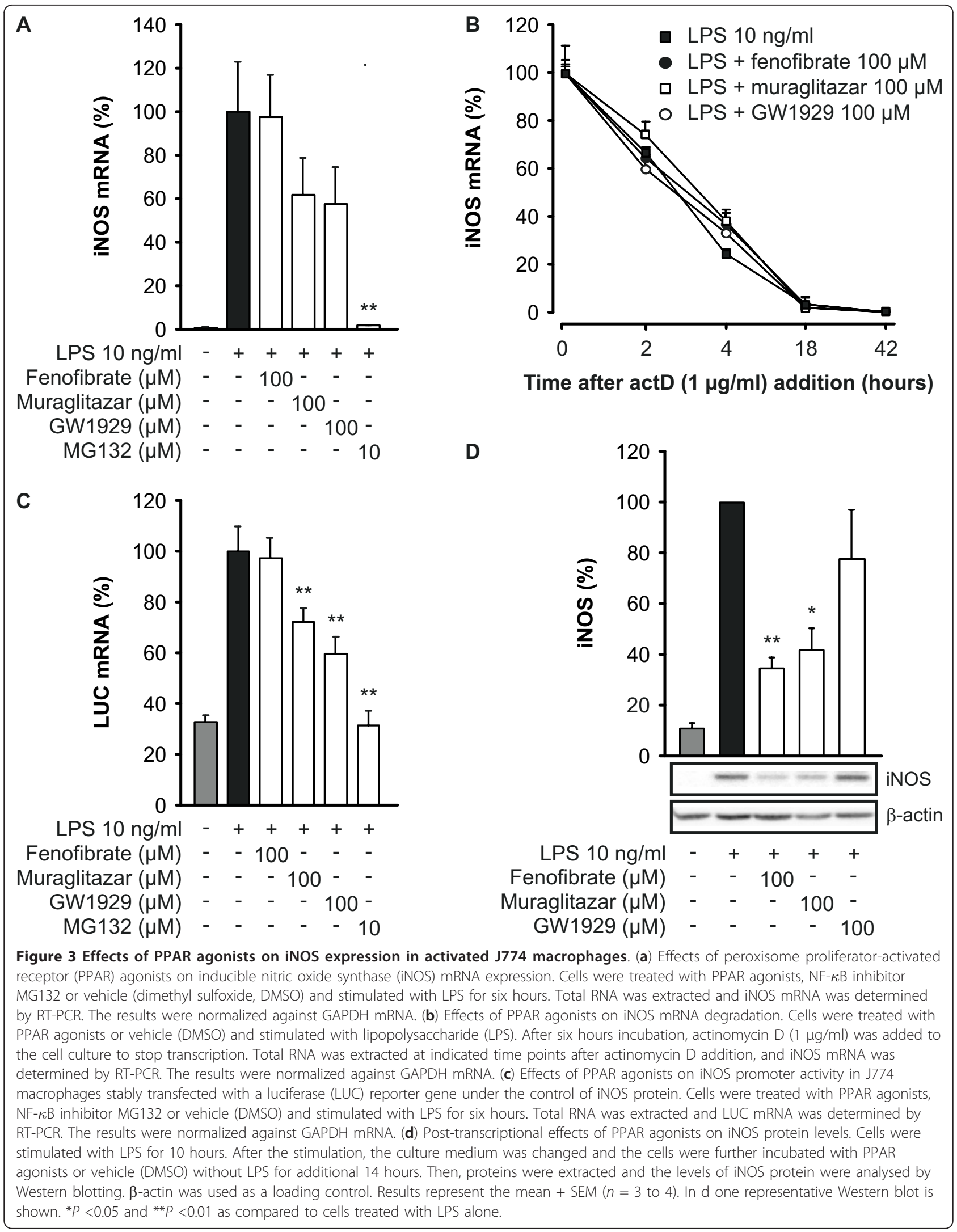



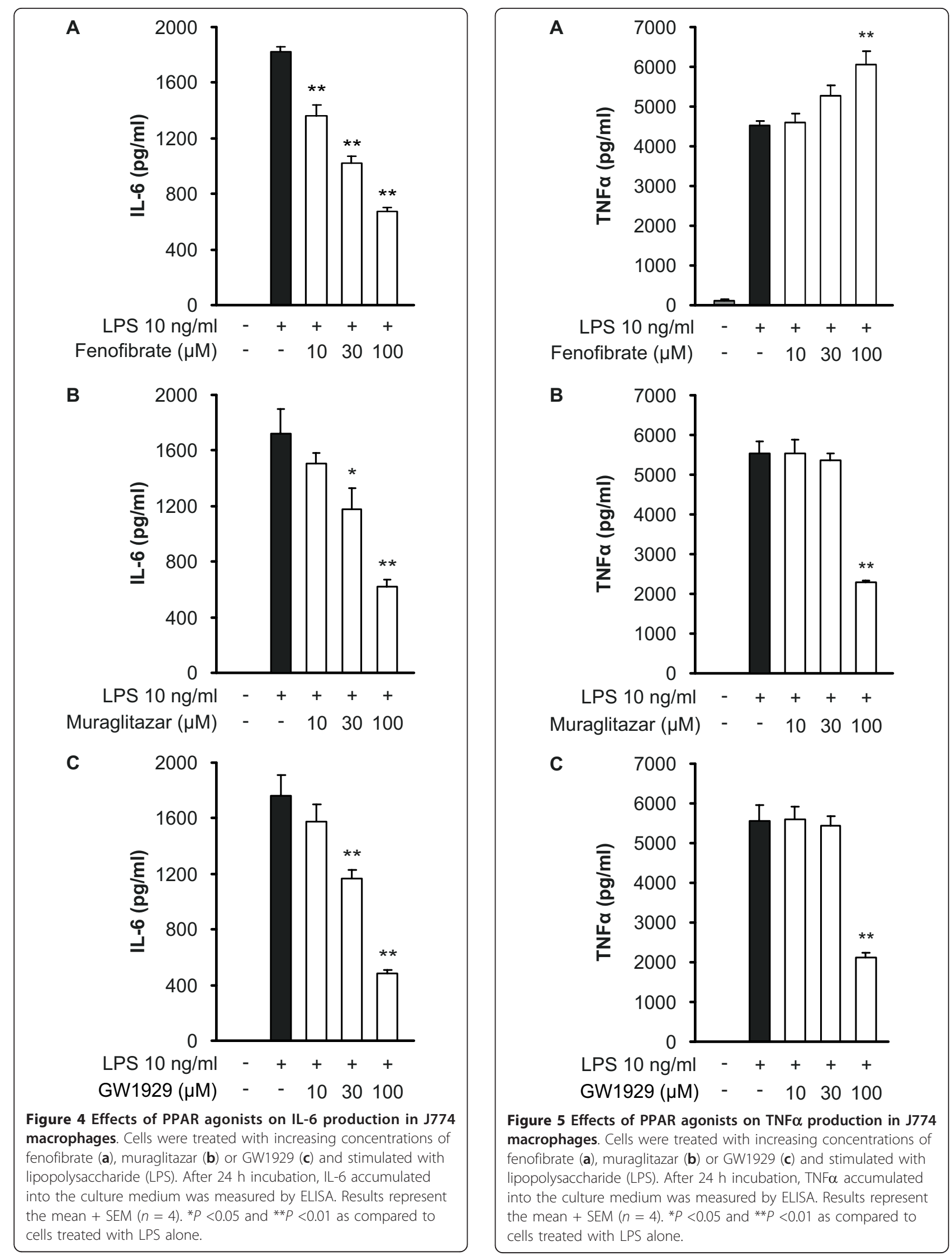


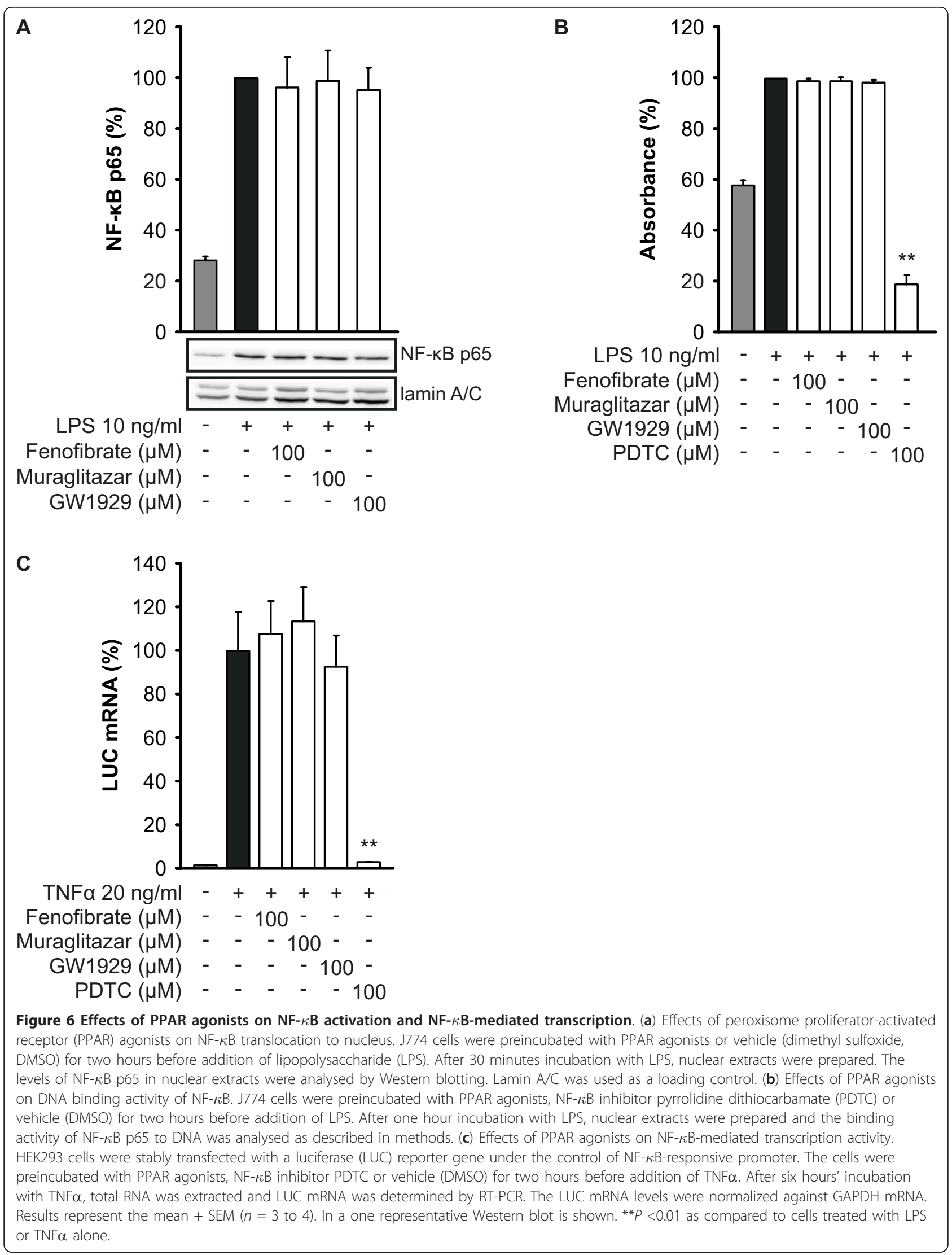




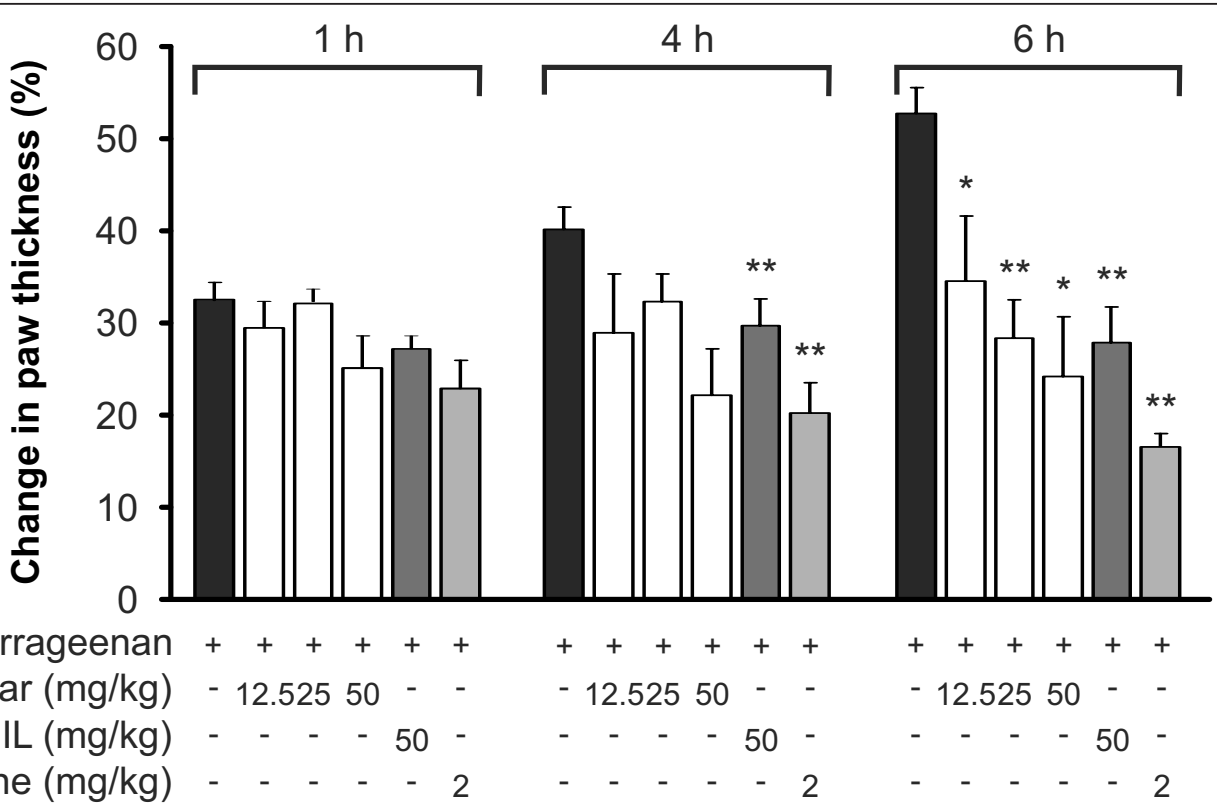

Figure 7 Effect of muraglitazar on carrageenan-induced paw oedema in the mouse. Muraglitazar, inducible nitric oxide synthase (iNOS) inhibitor L-NIL, dexamethasone or vehicle (2.0\% CMC) were given to animals per os 1 hour prior to carrageenan injection (1\%). Paw oedema was measured before and one, four and six hours after carrageenan injection by micrometer. Oedema is expressed as increase in paw thickness at indicated time points compared to thickness before carrageenan. Values are mean + SEM $(n=6) .{ }^{*} P<0.05$ and ${ }^{* *} P<0.01$ as compared to mice treated with carrageenan alone.

in carrageenan-induced inflammation. In line with the previous series, muraglitazar attenuated carrageenaninduced paw oedema (Figure 8a). Muraglitazar also decreased the levels of IL- 6 , TNF $\alpha$ and iNOS mRNA by $80 \%, 54 \%$ and $64 \%$, respectively (Figure $8 \mathrm{~b}-\mathrm{d}$ ).

\section{Discussion}

The present findings show that muraglitazar has antiinflammatory properties both in in vitro and in vivo models. The results suggest that the anti-inflammatory effects of muraglitazar reflect the agonistic action through both PPAR $\alpha$ and PPAR $\gamma$. To our knowledge, this is the first report describing the effects of dual PPAR $\gamma / \alpha$ agonists on inflammatory responses.

In support of the present findings, previous reports also describe the inhibitory effects of PPAR $\gamma$ or PPAR $\alpha$ agonists on inflammatory mediators in cell culture experiments [22]. PPAR $\gamma$ and PPAR $\alpha$ ligands have been reported to decrease plasma levels of proinflammatory cytokines in diabetic and hyperlipidemic patients [23]. In our experiments, PPAR $\alpha$ and PPAR $\gamma$ agonists had somewhat different effects on IL-6, TNF $\alpha$ and iNOS expression. All the agonists reduced IL-6 production in a similar potency. However, fenofibrate was not able to decrease TNF $\alpha$ production or iNOS mRNA levels, contrary to the effects of GW1929 or muraglitazar. On the other hand, unlike GW1929, muraglitazar and fenofibrate were able to decrease iNOS protein levels still at post-transcriptional time points. This suggests that activation of PPAR $\alpha$ and PPAR $\gamma$ regulate different pathways in the LPS-activated inflammatory cascades. The effects of PPAR agonists on iNOS expression are supported by our previous findings showing that PPAR $\alpha$ agonists WY14643 and GW7647 regulate iNOS expression by enhancing its degradation [19]. The present results imply that the effect of muraglitazar on TNF $\alpha$ production is mediated by the PPAR $\gamma$ component of action and on IL-6 production and iNOS expression by both PPAR $\alpha$ and PPAR $\gamma$ components of action. Especially, as for the inhibition of iNOS expression, muraglitazar seems to be a more potent inhibitor than fenofibrate or GW1929 alone. This is explained by the findings that PPAR $\gamma$ (but not PPAR $\alpha$ ) activation inhibits iNOS transcription and PPAR $\alpha$ (but not PPAR $\gamma$ ) activation has an effect at post-transcriptional level, while muraglitazar (as expected) has both of those effects. Thus the results suggest that combining the effects of PPAR $\alpha$ and PPAR $\gamma$ by using a dual PPAR $\gamma / \alpha$ agonist results in improved anti-inflammatory action as compared to PPAR $\alpha$ or PPAR $\gamma$ agonists alone.

In the present study, muraglitazar reduced iNOS mRNA expression and promoter activity but did not affect the activity of NF- $\kappa \mathrm{B}$, which is an important transcription factor for iNOS and IL-6 genes. According to our preliminary experiments, muraglitazar did not affect the activation of STAT1 or IRF1 either. Although the activity of NF- $\kappa$ B was not altered, it is possible that muraglitazar regulates 


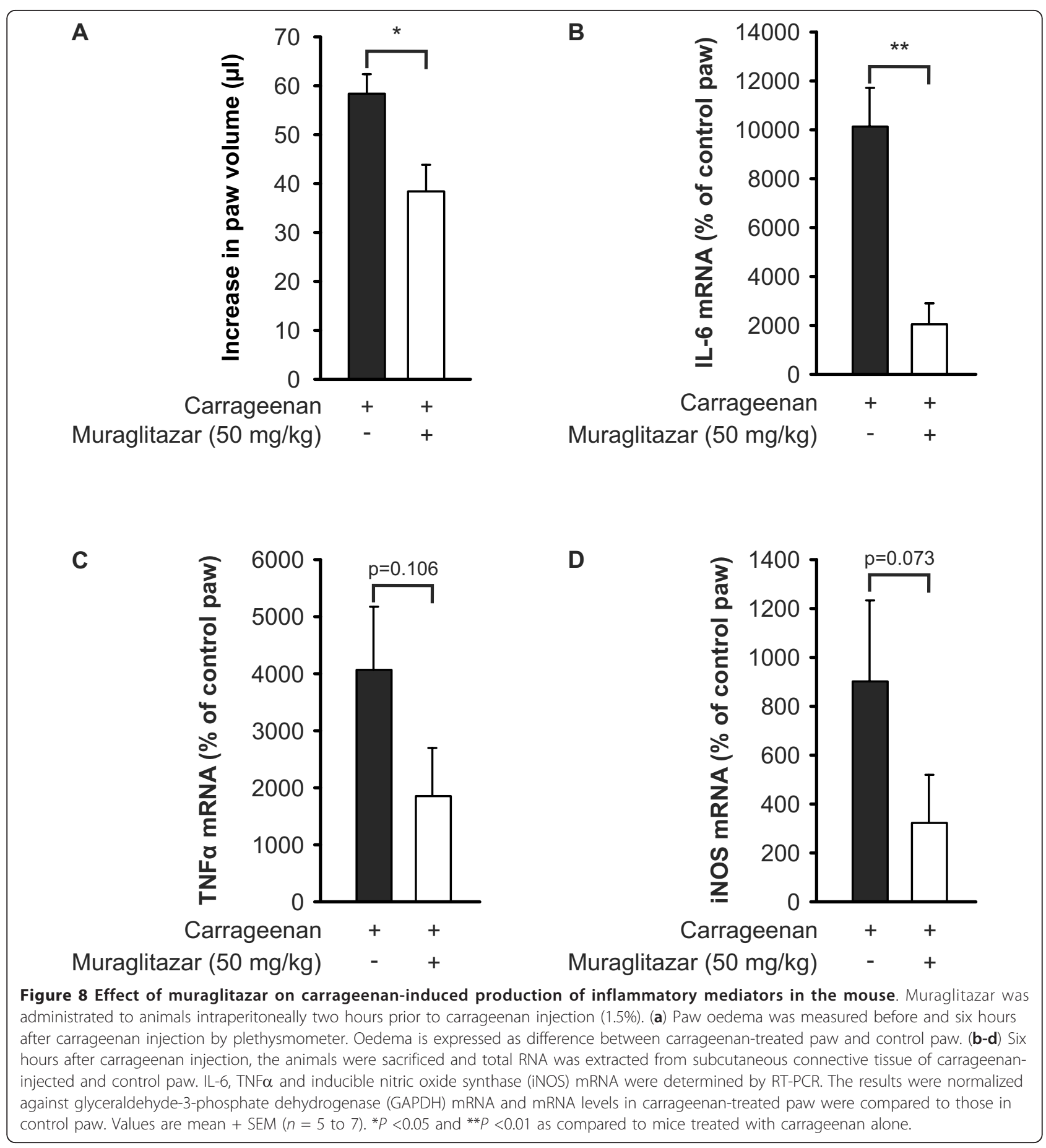

the transcription machinery in a more complicated manner. Still, further studies are needed to uncover the detailed target of muraglitazar in the transcriptional activation of iNOS.

There is evidence suggesting that PPAR $\gamma$ and PPAR $\alpha$ agonists attenuate experimentally induced arthritis in murine models. Tomita et al. [24] and Sumariwalla et al. [25] showed that PPAR $\gamma$ agonists THR0921 and
CLX-090717, respectively, reduced clinical signs of synovitis in collagen-induced arthritis in the mouse. THR0921 also decreased the circulating levels of IgG antibody to the collagen used in immunization [24]. Koufany et al. [26] reported that thiazolidinediones rosiglitazone and pioglitazone reduced synovial expression of TNF $\alpha$, IL-1 $\beta$ and basic fibroblast growth factor and clinical signs of synovitis in Freund's adjuvant-induced 
arthritis in rats. However, less is known about the possible effects of PPAR $\alpha$ agonists in inflammation models. Okamoto et al. [12] showed that fenofibrate decreased signs of arthritis and, to a lesser extent, paw oedema in Freund's adjuvant-induced arthritis in rats.

In the present study, we extend the previous data by showing that muraglitazar significantly decreased carrageenan-induced paw inflammation in mice. Carrageenan-induced paw oedema is a widely used model in inflammation research. It represents features of acute inflammation and innate immune responses and is useful for primary screening of therapeutic efficacy of novel anti-inflammatory agents [27]. Carrageenan-induced inflammation has been described to occur in two phases. The first and short-lasting phase starts almost immediately after the injection of carrageenan. The inflammation during this phase is local and the most abundant mediators are histamine, serotonin and kinins. The second phase starts in one to two hours after carrageenan injection and has been described to involve the activation of inflammatory cells, including macrophages. The expression of iNOS and COX-2, and the synthesis of prostaglandins, oxygen-derived free radicals, TNF $\alpha$, IL$1 \beta$ and IL-6 are increased in the inflamed tissue [28-30]. In our experiments, muraglitazar did not reduce paw oedema at early time points, that is, during the first phase of inflammation, while the anti-inflammatory effects at later time points were clear. The results of the effects of muraglitazar on paw oedema and inflammatory gene expression in mice are in line with our results in vitro, where muraglitazar reduced the production of NO, IL- 6 and TNF $\alpha$ and the expression of iNOS. These results show that muraglitazar has anti-inflammatory potency also in vivo.

During the last years the safety aspects of PPAR agonists have been discussed. Rosiglitazone was withdrawn from the market in Europe in September 2010, since it had been found to increase the risk of myocardial infarction in diabetic patients [31]. Fibrates, on the other hand, were suggested to increase the risk of myopathy, hepatotoxicity, cholecystitis and deep venous thrombosis [32]. However, in detailed studies, the increased risk of myocardial infarction has specifically been linked to rosiglitazone [33], while the other thiazolidinedione on the market, pioglitazone, seems to be a rather safe drug [34,35]. In addition, fibrates did not show increased risk of serious drug-related adverse events in a recently published meta-analysis when they were used as a monotherapy for the treatment of dyslipidemia [36]. Thus, it seems so far that the side effects of PPAR agonists are compound-dependent and not associated with the mechanism of action, and the advantages of these drugs in diabetes and dyslipidemia are markedly greater than the possible disadvantages.
Muraglitazar has been reported to have similar cardiovascular side effects as rosiglitazone, at least when combined with sulfonylureas or metformin [37]. Because of the adverse effects, muraglitazar's developer BristolMyers Squibb decided to discontinue further development of the drug in May 2006. Nevertheless, although the safety data published need to be considered, it is worth noticing that only little knowledge of using muraglitazar in nondiabetic patients is available. Thus, further studies are needed to establish the safety of muraglitazar and other dual PPAR $\gamma / \alpha$ agonists in other possible indications than diabetes.

The connection between metabolism and inflammation is interesting and there is lots of research activity going on in that area at this time. As many studies have already suggested, PPARs might be an important link between these two complex systems, and as shown in the present study, PPAR agonists have anti-inflammatory properties in classical inflammatory models. It has been shown that a good treatment of metabolic diseases reduces the low-grade inflammation associated with obesity [38]. But could the modification of metabolic pathways reduce the inflammatory responses associated to classical inflammatory diseases? This is a question we will be interested in answering in the future.

\section{Conclusions}

The present study shows that muraglitazar has several anti-inflammatory effects in activated macrophages and in carrageenan-induced inflammation in the mouse, reflecting its activity on both PPAR $\alpha$ and PPAR $\gamma$. The results strengthen the previous evidence of the connection of metabolism and inflammation. Understanding this connection in more detail might open a new avenue in the treatment of chronic inflammatory diseases in the future.

\section{Abbreviations}

CMC: carboxymethyl cellulose; DMSO: dimethyl sulfoxide; El: electron ionization; ESI: electrospray ion source; FTICR: Fourier transform ion cyclotron resonance; GAPDH: glyceraldehyde-3-phosphate dehydrogenase; IL-6: interleukin 6; iNOS: inducible nitric oxide synthase; L-NIL: $N^{6}$-(1-iminoethyl)-Llysine; LPS: lipopolysaccharide; NF-KB: nuclear factor kappa B; NO: nitric oxide; PDTC: pyrrolidine dithiocarbamate; PPAR: peroxisome proliferatoractivated receptor; SEM: standard error of mean; TBS: tri-buffered saline; TNFa: tumour necrosis factor $a$; TZDs: thiazolidinediones

\section{Authors' contributions}

EP carried out most of the experiments, participated in the design of the study and interpretation of the results, and drafted the manuscript. TL and ML participated in the experimental analyses and design of the study. MFY and MZA carried out the first series (Figure 7) of the in vivo assays. AK and PHA synthesized muraglitazar. EM conceived and coordinated the study, and supervised its design and conduction and writing of the manuscript. All authors read and approved the final manuscript.

\section{Competing interests}

The authors declare that they have no competing interests. 


\section{Acknowledgements}

Ms. Meiju Kukkonen, Mrs. Salla Hietakangas and Ms. Petra Miikkulainen are acknowledged for their excellent technical assistance and Mrs. Heli Määttä for her skillful secretarial help. This study was supported by grants from the Academy of Finland, the Medical Research Fund of Tampere University Hospital and the Rheumatology Research Foundation. EP is a student in the national FinPharma doctoral program.

\section{Author details}

${ }^{1}$ The Immunopharmacology Research Group, University of Tampere School of Medicine and Tampere University Hospital, Medisiinarinkatu 3, Tampere, Fl-33014, Finland. ${ }^{2}$ School of Pharmaceutical Sciences, Universiti Sains Malaysia, Minden, MY-11800, Pulau Pinang, Malaysia. ${ }^{3}$ Department of Chemistry, University of Eastern Finland, Joensuu Campus, Yliopistokatu 7, Joensuu, Fl-80101, Finland.

Received: 20 August 2012 Revised: 14 February 2013

Accepted: 9 April 2013 Published: 17 April 2013

\section{References}

1. Hamilton JA, Tak PP: The dynamics of macrophage lineage populations in inflammatory and autoimmune diseases. Arthritis Rheum 2009, 60:1210-1221.

2. Gierut A, Perlman $H$, Pope RM: Innate immunity and rheumatoid arthritis. Rheum Dis Clin North Am 2010, 36:271-296.

3. Zeyda M, Stulnig TM: Adipose tissue macrophages. Immunol Lett 2007, 112:61-67.

4. Schenk S, Saberi M, Olefsky JM: Insulin sensitivity: modulation by nutrients and inflammation. J Clin Invest 2008, 118:2992-3002.

5. Mathieu P, Lemieux I, Despres JP: Obesity, inflammation, and cardiovascular risk. Clin Pharmacol Ther 2010, 87:407-416.

6. Lago F, Dieguez C, Gomez-Reino J, Gualillo O: Adipokines as emerging mediators of immune response and inflammation. Nat Clin Pract Rheumatol 2007, 3:716-724.

7. Shapiro H, Lutaty A, Ariel A: Macrophages, meta-inflammation, and immuno-metabolism. ScientificWorldJournal 2011, 11:2509-2529.

8. Gordon S: Alternative activation of macrophages. Nat Rev Immunol 2003, 3:23-35.

9. Fruchart JC: Peroxisome proliferator-activated receptor-alpha (PPARa): At the crossroads of obesity, diabetes and cardiovascular disease. Atherosclerosis 2009, 205:1-8.

10. Fuentes $L$, Roszer $T$, Ricote $M$ : Inflammatory mediators and insulin resistance in obesity: role of nuclear receptor signaling in macrophages. Mediators Inflamm 2010, 2010:219583.

11. Giaginis C, Giagini A, Theocharis S: Peroxisome proliferator-activated receptor- $\gamma$ (PPAR- $\gamma$ ) ligands as potential therapeutic agents to treat arthritis. Pharmacol Res 2009, 60:160-169.

12. Okamoto $\mathrm{H}$, Iwamoto $\mathrm{T}$, Kotake $\mathrm{S}$, Momohara S, Yamanaka H, Kamatani N: Inhibition of NF-KB signaling by fenofibrate, a peroxisome proliferatoractivated receptor-a ligand, presents a therapeutic strategy for rheumatoid arthritis. Clin Exp Rheumatol 2005, 23:323-330.

13. Devasthale PV, Chen S, Jeon Y, Qu F, Shao C, Wang W, Zhang H, Cap M, Farrelly D, Golla R, Grover G, Harrity T, Ma Z, Moore L, Ren J, Seethala R, Cheng L, Sleph P, Sun W, Tieman A, Wetterau JR, Doweyko A, Chandrasena G, Chang SY, Humphreys WG, Sasseville VG, Biller SA, Ryono DE, Selan F, Hariharan N, Cheng PT: Design and synthesis of N-[(4Methoxyphenoxy)carbonyl]-N-[[4-[2-(5-methyl-2-phenyl-4-oxazolyl) ethoxy]phenyl]methyl]glycine [Muraglitazar/BMS-298585], a novel peroxisome proliferator-activated receptor $a / \gamma$ dual agonist with efficacious glucose and lipid-lowering activities. J Med Chem 2005, 48:2248-2250.

14. Buse JB, Rubin CJ, Frederich R, Viraswami-Appanna K, Lin KC, Montoro R, Shockey G, Davidson JA: Muraglitazar, a dual ( $a / \gamma)$ PPAR activator: a randomized double-blind, placebo-controlled, 24-week monotherapy trial in adult patients with type 2 diabetes. Clin Ther 2005, 27:1181-1195.

15. Kendall DM, Rubin CJ, Mohideen P, Ledeine JM, Belder R, Gross J, Norwood P, O'Mahony M, Sall K, Sloan G, Roberts A, Fiedorek FT, DeFronzo RA: Improvement of glycemic control, triglycerides, and HDL cholesterol levels with muraglitazar, a dual $(a / \gamma)$ peroxisome proliferatoractivated receptor activator, in patients with type 2 diabetes inadequately controlled with metformin monotherapy. Diabetes Care 2006, 29:1016-1023.

16. Kleinert H, Euchenhofer C, Ihrig-Biedert I, Förstermann U: Glucocorticoids inhibit the induction of nitric oxide synthase II by down-regulating cytokine-induced activity of transcription factor nuclear factor-кB. $\mathrm{Mol}$ Pharmacol 1996, 4:15-21.

17. Green LC, Wagner DA, Glogowski J, Skipper PL, Wishnok JS

Tannenbaum SR: Analysis of nitrate, nitrite, and [15N]nitrate in biological fluids. Anal Biochem 1982, 126:131-138.

18. Bradford MM: A rapid and sensitive method for the quantitation of microgram quantities of protein utilizing the principle of protein-dye binding. Anal Biochem 1976, 7:248-254.

19. Paukkeri EL, Leppänen $T$, Sareila O, Vuolteenaho K, Kankaanranta $H$, Moilanen E: PPARa agonists inhibit nitric oxide production by enhancing iNOS degradation in LPS-treated macrophages. Br J Pharmacol 2007, 152:1081-1091.

20. Kleinert H, Schwarz PM, Föstermann U: Regulation of the expression of inducible nitric oxide synthase. Biol Chem 2003, 384:1343-1364.

21. Brown KD, Claudio E, Siebenlist U: The roles of the classical and alternative nuclear factor- $\mathrm{kB}$ pathways: potential implications for autoimmunity and rheumatoid arthritis. Arthritis Res Ther 2008, 10:212.

22. Moraes LA, Piqueras L, Bishop-Bailey D: Peroxisome proliferator-activated receptors and inflammation. Pharmacol Ther 2006, 110:371-385.

23. Libby P, Plutzky J: Inflammation in diabetes mellitus: role of peroxisome proliferator-activated receptor- $a$ and peroxisome proliferator-activated receptor- $\gamma$ agonists. Am J Cardiol 2007, 99:27B-40B.

24. Tomita T, Kakiuchi Y, Tsao PS: THR0921, a novel peroxisome proliferatoractivated receptor gamma agonist, reduces the severity of collageninduced arthritis. Arthritis Res Ther 2006, 8:R7.

25. Sumariwalla PF, Palmer CD, Pickford LB, Feldmann M, Foxwell BM, Brennan FM: Suppression of tumour necrosis factor production from mononuclear cells by a novel synthetic compound, CLX-090717. Rheumatology 2009, 48:32-38.

26. Koufany M, Moulin D, Bianchi A, Muresan M, Sebillaud S, Netter $P$, Weryha $G$, Jouzeau JY: Anti-inflammatory effect of antidiabetic thiazolidinediones prevents bone resorption rather than cartilage changes in experimental polyarthritis. Arthritis Res Ther 2008, 10:R6.

27. Paw edema. In Drug discovery and Evaluation: Pharmacological Assays.. 2 edition. Edited by: Vogel HG. New York: Springer; 2002:759-762.

28. Salvemini D, Wang ZQ, Wyatt PS, Bourdon DM, Marino MH, Manning PT, Currie MG: Nitric oxide: a key mediator in the early and late phase of carrageenan-induced rat paw inflammation. Br J Pharmacol 1996, 118:829-838.

29. Loram LC, Fuller A, Fick LG, Cartmell T, Poole S, Mitchell D: Cytokine profiles during carrageenan-induced inflammatory hyperalgesia in rat muscle and hind paw. J Pain 2007, 8:127-136.

30. Morris CJ: Carrageenan-induced paw edema in the rat and mouse. Methods Mol Biol 2003, 225:115-121.

31. Nissen SE, Wolski K: Effect of rosiglitazone on the risk of myocardial infarction and death from cardiovascular causes. N Engl J Med 2007 356:2457-2471.

32. Davidson MH, Armani A, McKenney JM, Jacobson TA: Safety considerations with fibrate therapy. Am J Cardiol 2007, 99:3C-18C.

33. Home PD, Pocock SJ, Beck-Nielsen H, Curtis PS, Gomis R, Hanefeld M, Jones NP, Komajda M, McMurray JJ, RECORD Study Team: Rosiglitazone evaluated for cardiovascular outcomes in oral agent combination therapy for type 2 diabetes (RECORD): a multicentre, randomised, openlabel trial. Lancet 2009, 373:2125-2135.

34. Lincoff AM, Wolski K, Nicholls SJ, Nissen SE: Pioglitazone and risk of cardiovascular events in patients with type 2 diabetes mellitus: a metaanalysis of randomized trials. JAMA 2007, 298:1180-1188.

35. Dormandy J, Bhattacharya M, van Troostenburg de Bruyn AR, PROactive investigators: Safety and tolerability of pioglitazone in high-risk patients with type 2 diabetes. Drug Saf 2009, 32:187-202.

36. Jun M, Foote C, LV J, Neal B, Patel A, Nicholls SJ, Grobbee DE, Cass A, Chalmers J, Perkovic V: Effects of fibrates on cardiovascular outcomes: a systematic review and meta-analysis. Lancet 2010, 375:1875-1884.

37. Nissen SE, Wolski K, Topol EJ: Effect of muraglitazar on death and major adverse cardiovascular events in patients with type 2 diabetes mellitus JAMA 2005, 294:2581-2586. 
38. Kontunen $P$, Vuolteenaho $K$, Nieminen $R$, Lehtimaki L, Kautiainen $H$, Kesaniemi Y, Ukkola O, Kauppi M, Hakala M, Moilanen E: Resistin is linked to inflammation, and leptin to metabolic syndrome, in women with inflammatory arthritis. Scand J Rheumatol 2011, 40:256-262.

doi:10.1186/ar4211

Cite this article as: Paukkeri et al: Anti-inflammatory properties of a dual PPARgamma/alpha agonist muraglitazar in in vitro and in vivo models. Arthritis Research \& Therapy 2013 15:R51.

Submit your next manuscript to BioMed Central and take full advantage of:

- Convenient online submission

- Thorough peer review

- No space constraints or color figure charges

- Immediate publication on acceptance

- Inclusion in PubMed, CAS, Scopus and Google Scholar

- Research which is freely available for redistribution

Submit your manuscript at www.biomedcentral.com/submit
C Biomed Central 